\title{
Effects of Wound Size, Amount of Sap, and Number of Blighted Nuts on Infection of Pistachio Organs by Neofusicoccum mediterraneum
}

J. Moral, Department of Plant Pathology, University of California Davis, Kearney Agricultural Research and Extension Center, Parlier 93648; and Department of Agronomy, University of Córdoba, Córdoba, Spain; and N. Ahimera, D. G. Felts, D. P. Morgan, and T. J. Michailides, ${ }^{\dagger}$ Department of Plant Pathology, University of California Davis, Kearney Agricultural Research and Extension Center

\begin{abstract}
Laboratory and field studies were conducted to determine the effects of wounding of nut exocarp, susceptibility period after wounding, and sap nut on infection of pistachio nut by Neofusicoccum mediterraneum, the main causal agent of panicle and shoot blight of pistachio. Under controlled conditions and in the field, detached nuts were inoculated with a conidial suspension $30 \mathrm{~min}$ before or after wounding. In addition, a $30-\mu l$ drop of pistachio sap was placed on the surface of noninjured nuts $30 \mathrm{~min}$ before or after they were wounded and then inoculated. Wounding increased the disease severity under both controlled and field conditions. The addition of sap increased the susceptibility of nuts under controlled conditions but not in the field, possibly due to dried sap blocking the pathogen infection. When nuts of Kerman, Kalehghouchi, and Golden Hills pistachio were wounded and inoculated at different time periods after wounding; the nuts of the three cultivars were highly

susceptible to pathogen infection during at least the first $24 \mathrm{~h}$ after wounding. Under field conditions, there was not a clear effect of increasing the number of inoculated nuts per panicle or the inoculation position (basal or apical) in killing (blight) of the panicle. Conversely, inoculations conducted with mycelial plugs resulted in higher disease, increased the proportion of dead panicles, and resulted in faster symptom expression than inoculations conducted with a conidial suspension. To determine the temporal infection pattern, leaves and panicles were regularly collected from different orchards from 2004 to 2007 and the pathogen was isolated on medium. Important differences in latent infection were detected between years and orchards, with nut and rachis being, in general, the tissues most susceptible to infection. Results of this study help in better understanding the dynamic of infection and colonization of pistachio by $N$. mediterraneum.
\end{abstract}

The United States of America and Iran are global leaders for pistachio (Pistacia vera L.) production. In the United States, the major pistachio acreage is located in Mediterranean, arid, and semiarid regions, mainly in California and, to some extent, in Arizona. In California, female ' Kerman' and male 'Peters' pistachio are dominant but the majority of the new plantings are 'Golden Hill' (female cultivar), along with 'Randy' (male) (Parfitt et al. 2007). The major cultivars grown in Iran are the traditional 'Momtaz', 'Ohadi', and 'Kalehghouchi' (Parfitt et al. 2005).

Panicle and shoot blight is the most important disease of pistachio in California (Michailides 1991). Eight species of Botryosphaeriaceae and one species of Diaporthe are associated with this disease, with Neofusicoccum mediterraneum being the dominant ( $>80 \%$ of isolates) species (Chen et al. 2014). The affected pistachio plants show different syndromes, with the collapse of panicles (i.e., panicle blight) being the most destructive for yield. The disease was discovered in one of the oldest pistachio orchards in Butte County, CA but, over the span of 10 years, has spread all over the acreage where pistachio plants are grown (e.g., Kern, Tulare, Kings, and Fresno Counties) except the "West Side". From 1996 to 1999, severe epidemics of the disease were observed in orchards throughout the central San Joaquin Valley that resulted in substantial yield loss (Michailides and Morgan 1992, 2004). At the time, when no fungicides were registered to control this disease, cultural practices such as pruning to reduce the fungal inoculum or use of lower sprinklers to prevent water impact on the tree were the only practices that the growers performed to manage the disease (Michailides and Morgan 2004).

Intensive research, though, over the last two and a half decades has resulted in the registration of a large number of fungicides, giving growers many choices for management of the disease (Adaskaveg

${ }^{\dagger}$ Corresponding author: T. J. Michailides; E-mail: tjmichailides@ucanr.edu

J. Moral and N. Ahimera contributed equally to this study.

Accepted for publication 16 July 2017.

(c) 2017 The American Phytopathological Society et al. 2017). Application of efficacious fungicide at the right timing (infection events) provides consistent control of the disease (Michailides and Morgan 2004; Morgan et al. 2009). Unfortunately, once the pathogen has been established in the lignified tissues of pistachio (blighted shoots and cankers from infections of panicles or male flowers), it is difficult to control because registered fungicides only protect young tissues from infection and lack any postinfection or real systemic activity against the pathogen.

The pathogen produces abundant pycnidia (anamorph phase) that easily cover all infected tree parts such as retained rachises and petioles, blighted shoots, nut mummies, blighted buds, and the central part of cankers that developed in wood of previously blighted panicles and male flowers where fungicides cannot reach. Blighted shoots, rachises, and branch cankers constitute the main source of primary inoculum by providing pycnidiospores for several years (Ahimera et al. 2003, 2004; Michailides 1991; Michailides and Morgan 2004). A recent survey of commercial orchards in Californian revealed the presence of only the pycnidial stage in this crop (Chen et al. 2014). However, the perithecial stage (teleomorph phase) of several Botryosphaeriaceae spp. have been reported in California on giant Sequoia and coastal redwood (Worrall et al. 1986), and sporadically on almond, blackberry, cedar, hawthorn, olive, and walnut (Inderbitzin et al. 2010; Michailides and Morgan 2004; Moral et al. 2010). Fortunately, the teleomorph of the dominant species in pistachio, N. mediterraneum, has been described only in southern Spain (Moral et al. 2015).

In California pistachio, pycnidiospores cause the primary infections during early spring and latent infection later during the season after rain events (Michailides 1991; Michailides and Morgan 2004; Morgan et al. 2009). For successful infection, the pathogen requires periods of free moisture (wetness periods) or high relative humidity to produce the cirrhi bearing conidia, which require splashing or dripping water for dispersal. Thereafter, spore dispersal and infection occur during the rainy seasons, which occur mainly in fall to winter and early spring in Mediterranean climates (Ahimera et al. 2004). The infections then remain latent until suitable conditions for symptom development (temperatures $>27^{\circ} \mathrm{C}$ ) occur late in the season (Michailides and Morgan 1992; Ntahimpera et al. 2002). Disease severity can suddenly increase on infected panicles and kill them in a short time during 
August if weather conditions are conducive (Michailides et al. 2016). The panicle collapse at the end of the season could depend on the severity of the infections, which occurred during the rainfall periods (usually during the spring) and on the infection site (basal versus apical) of panicle; however, this collapse has never been studied.

The Botryosphaeriaceae spp. producing Fusicoccum-like conidia (i.e., fusiform, hyaline conidia belonging to several species of this genus that were mostly indistinguishable such as Botryosphaeria dothidea and $N$. mediterraneum species) have been found by earlier researchers to be both wound and nonwound pathogens (Creswell and Milholland 1987; Michailides 1991; Milholland 1972). Botryosphaeriaceae spp. have been also described invading tissues that showed no apparent wounds although, in general, wounded tissues are infected more readily and show larger lesions (Brown and Hendrix 1981; Michailides 1991; Milholland 1972). Penetration of nonwounded tissues takes place through natural openings such as open stomata (Michailides 1991; Milholland 1972) or lenticels (Michailides 1991) but direct penetration is, at most, unusual (Kim et al. 1999). In pistachio orchards, it has been recently suggested that wounds from the feeding of hemipteran insects (Thyanta pallidovirens, Acrosternum hilare, and Leptoglossus clypealis) constitute an important infection point for the pathogen. In this pistachio-fungus-insect interaction, the presence of pistachio sap can provide nutrients for the pathogen on the one hand, and protect the wound on the other (Michailides and Morgan 2016). Finally, the cultivar resistance or susceptibility could have an important role in this interaction but it has scarcely been studied.

Because the severity of symptoms of panicle and shoot blight of pistachio depends on different factors such as nut wounding, cultivar resistance, and the type of initial infection, the objectives of this work were to study (i) the effect of nut wounding or adding sap on infection by $N$. mediterraneum, (ii) the susceptibility period of the nut to pathogens after wounding on three main pistachio cultivars, (iii) the effect of number of inoculated nuts and their position in the panicle, and (iv) the susceptibility of the different pistachio organs across several years.

\section{Materials and Methods}

Effects of sap and wound on pistachio nut infection. Trial 1. Developing nuts were collected from disease-free pistachio trees at Kearney Agricultural Research and Extension (KARE) Center (Parlier, CA). The nut was squeezed with a garlic press and the obtained sap was filtered through four layers of cheesecloth. For nut inoculation experiments, developing nuts, which were harvested 115 days after full bloom from KARE Center, were surface sterilized for $3 \mathrm{~min}$ in a $0.5 \% \mathrm{NaClO}$ solution after adding $0.001 \%$ Tween 20 , and dried on clean paper towels. The nuts were arranged in six rows of 10 nuts each by placing them on a wire screen in plastic humid chambers $(31.5$ by 23.5 by $10.0 \mathrm{~cm}$ ) with about $200 \mathrm{ml}$ of water added to maintain high relative humidity ( $>95 \%$ ). The rows corresponded to each of the following six treatments: (i) nuts wounded but not inoculated (noninoculated control, W), (ii) nuts inoculated without wounding (I), (iii) nuts wounded $30 \mathrm{~min}$ before inoculation (WI), (iv) nuts wounded 30 min after inoculation (IW), (v) a 30- $\mu$ l drop of sap was placed on the surface of wounded nuts that were inoculated 30 min latter (SI), and (vi) a 30- $\mu$ l drop of sap was added to wounded nuts $30 \mathrm{~min}$ after inoculation (IS). Wounding was a superficial puncture with a 1.3-mm dissecting needle to mimic large hemipteran insect injury, which left a small amount of sap exuding from the wound (Michailides and Morgan 2016). Inoculation consisted of depositing a $30-\mu l$ drop of $N$. mediterraneum at $5 \times 10^{4}$ spores $/ \mathrm{ml}$ with a micropipette on a marked area of each nut. In all experiments of the present study, one reference $N$. mediterraneum isolate (2C10) from an affected pistachio tree was used, except for trial 3, in which the isolate 1D02 was used. Both isolates are maintained in the collections of the Department of Plant Pathology at the University of CaliforniaDavis (Kearney Agricultural Center in Parlier). The proportions of infected nuts (disease incidence) and of affected area per nut (disease severity, from 0 to $100 \%$ ) were recorded at 7 and 14 days after inoculation and the relative area under the disease progress curve (RAUDPC) was calculated by trapezoidal integration. Three repetitions (30 nuts each) per treatment were used. The whole experiment was repeated twice during two consecutive years (2006 and 2007).

The same six treatments were conducted under field conditions in 2006 and 2007 in a 15- to 16-year-old Kerman orchard in the KARE Center. In this case, we selected three pistachio trees, 18 panicles/ tree, and 3 panicles/treatment and tree. The number of diseased nuts was recorded weekly until the end of the season and the RAUDPC was calculated. In the present study, all the field inoculations were performed in the late afternoon to avoid high temperatures. After inoculation, each panicle was covered with a transparent plastic bag that was sprayed inside with water secured at the base of the panicle and covered with a brown paper bag for $18 \mathrm{~h}$ to prevent sunburn.

Effect of the length of time between wounding and inoculation. Trial 2. Healthy panicles were collected from one experimental Kerman orchard at the KARE Center during August 2014. The nuts were manually separated from rachises, washed, and disinfested as above. Forty nuts were placed inside of a humid chamber with water, as previously described. In this case, each plastic container corresponded to each of the following seven treatments: (i) sterile water injection in the nut using a 1-ml disposable syringe (noninoculated control-1, Inj); (ii) nuts were only wounded using a $1.3-\mathrm{mm}$ dissecting needle (noninoculated control-2, W); (iii) $20 \mu \mathrm{l}$ of a conidial suspension was injected under the epidermis of each nut using a disposable syringe (InjI); (iv) a 20- $\mu$ l drop of conidial suspension $\left(5 \times 10^{4}\right.$ spores $\left./ \mathrm{ml}\right)$ was deposited on a nonwounded nut (I); and (v), (vi) and (vii) a $20-\mu l$ drop of conidial suspension was deposited on wounded nuts at 0,4 , and $6 \mathrm{~h}$ after wounding, respectively (WI-0, -4 , and -6 , respectively). The whole trial was conducted twice using two humid chambers (with 40 nuts each) per experimental repetition.

Trial 3. Nuts of three of most important pistachio cultivars (Kalehghouchi, Kerman, and Golden Hills) were harvest at KARE Center at the end of July 2015 and used for a trial similar to the previous one. The nuts were washed, disinfested, and kept in humid chambers as describe above. Twelve nuts of each cultivar (two rows of six nuts each) were introduced in each plastic container. The inoculations were conducted using a $5 \times 10^{4}$ conidia/ml suspension of a reference $N$. mediterraneum isolate (1D02) and the treatments were similar to those described in trail 2: (i) wounded nuts (noninoculated control, W); (ii) inoculated and nonwounded nuts (I); and (iii), (iv), (v), and (vi) inoculated nuts at $0,6,12$, and $24 \mathrm{~h}$ after wounding, respectively (WI-0, $-6,-12$, and -24 , respectively). There were three replicate humid chambers (36 nuts/chamber) for each treatment. The whole experiment was conducted twice.

In both trials 2 and 3, the number of diseased nuts and the severity of symptoms (from 0 to $100 \%$ of nut surface) were recorded weekly and the RAUDPC was calculated.

Effect of the number and position in the cluster of the nuts infected by $N$. mediterraneum on the blight of clusters. To study the impact of the number of nuts infected per panicle on the final disease severity, four trials were performed in a Kerman orchard at the KARE Center.

Trial 4. In August 2006, 40 panicles were arbitrarily chosen from three pistachio trees and tagged. Half of the panicles were inoculated by firmly pressing one 3-mm mycelial plug of a 1-week-old $N$. mediterraneum culture (isolate $2 \mathrm{C} 10$ ) to each of one, two, three, four, or five nuts per panicle. The inoculated nuts were randomly selected in each panicle. The other half of the clusters were inoculated by depositing a $30-\mu l$ drop of $5 \times 10^{4}$ spores $/ \mathrm{ml}$ on one, two, three, four, or five nuts per panicle. All of the nuts were injured with a dissecting needle prior to their inoculation, as described earlier. In the treatment with five inoculated nuts per panicle, using either a mycelial plug or a spore suspension, the percentage of dead clusters was also monitored. Moreover, we added a new treatment in 2007, with clusters that were directly inoculated in the base of the rachis, using a mycelial plug. As a control, panicles were treated with a drop of sterile water or an agar plug without the pathogen, as described for the inoculation treatments. In all cases, four panicles were used for each treatment, with three replications per treatment. The entire experiment was conducted in two consecutive seasons, except for the inoculation in the base of the rachis, which was conducted only in 2007 . 
Trial 5. To study the effect of the position (apical or basal) of the infected nuts in the panicle blight, from one to five nuts in each position were inoculated as above. The experiment was conducted using 100 panicles in five replicated mature Kerman pistachio trees (20 panicles/tree) in 2006 and 2007. In both trials, the five control panicles were sprayed with water. The number of diseased nuts was periodically evaluated and the RAUDPC was calculated.

Trial 6. Panicles bearing from one to five naturally infected nuts from unsprayed trees were tagged in two orchards each in Glenn and San Joaquin Counties in early August 2006. The total number of nuts per panicle (looking healthy at that time) was also recorded. Twenty-five panicles were collected for each treatment in each county (Glenn and San Joaquin); in other words, five panicles bearing one, two, three, four, or five symptomatic nuts in each treatment. At 14 and 28 days after the initial counting, the number of infected nuts per panicle was evaluated and the RAUDPC was calculated.

Infection pattern of nut, rachis, leaf petiole, and the leaflet midvein. Trial 7. Healthy leaves and panicles were collected from four Kerman orchards in Glenn, San Joaquin, Merced, and Yolo Counties from 2004 to 2007. Because the orchard in Merced County had very low disease incidence in 2005, it was changed to a new one located in Yolo County in the following 2 years (Table 1). One leaf (with five to seven leaflets) and one panicle (with 15 to 25 nuts) from each of six replicated trees in each orchard were collected biweekly from early May through early September. The leaves, nuts, and rachises were washed and surface disinfested for $2 \mathrm{~min}$ in $0.05 \% \mathrm{NaOCl}$ with $0.001 \%$ Tween 20 and allowed to dry on double clean paper towels for 30 to $45 \mathrm{~min}$ in a laminar positive-airflow hood. Each main rachis, leaf petiole, and leaflet midrib was cut crosswise in 10 pieces and each nut in 5 pieces (across the length of each nut). Sectioned pieces were placed on potato dextrose agar (Difco Laboratories, Detroit) acidified with lactic acid $(2.5 \mathrm{ml}$, $25 \%$ [vol/vol] per liter of medium) in 9-cm Petri dishes. The position of each segment (from the apical end [position 1] to stem end [base or position 5]) and the fungal colonies growing from each segment were subsequently identified.

Data analysis. The experiments determining the effect of adding nut sap or of wounding to inoculate nut (trials 1 and 2) were conducted as randomized complete block designs in which humid chambers or trees were used as blocks. Because it was mainly interesting to study the effect of the treatments for each year or conditions (i.e., field or laboratory conditions), the six treatment means were separately subjected to analysis of variance (ANOVA). In all ANOVA, the means of different treatments were compared using Fisher's protected least significant differences at $P=0.05$. In addition, the treatments showing an average value equal to zero were not considered in the ANOVA. Subsequently, the normality and homogeneity of the variance were studied and arcsin transformation was used when needed.

In trial 2, ANOVA was applied to a completely randomized design, with two replicates (humid chambers) per treatment and 40 nuts per replicate. In trial 3, a split-plot design was used, with experiment runs as blocks, treatment as the main plot, cultivar as subplot, and humid chambers as replications. Both trials were repeated once, and data from repetitions of each trial were combined after checking for homogeneity of the experimental error variances by the $F$ test. In trial 4, factorial ANOVA was applied to study the effect of the number of inoculated nuts and inoculation method (spore suspension or mycelial plug) in the severity of symptoms for each year. For each treatment and year, the relationship between the number of inoculated nuts and the severity of symptoms was studied using Spearman rank correlations. Likewise, ANOVA were applied to study the effect of the different independent variables on the disease severity (RAUDPC) of the data from trials 5 and 6.

Finally, in trial 7 , in which we studied the effect of infection pattern on different pistachio tissues, the segment position was correlated with the infection percentage of each treatment (tissue, orchard, and year) using Spearman rank correlations. Likewise, a Pearson correlation was used to study the relationship between the infection percentages of the different pistachio tissues for the whole of the data. Finally, the average and standard deviation of the data for each year, orchard, and tissue were calculated without considering the segment position because it did not have any effect on the isolation percentage (Table 1). All the data were analyzed using Statistix (version 10; Statistix, Tallahassee, FL).

\section{Results}

Effects of sap and wound on pistachio nut infection. Trial 1. The first symptoms on the inoculated pistachio nuts were observed at 5 days after inoculation, forming concave and black spots characteristic of the disease. In the inoculation conducted under controlled conditions, adding the sap $30 \mathrm{~min}$ before or after inoculation of wounded nuts (SI or IS treatments) increased the disease severity with respect to the WI or IW treatments, although the SI treatment did not show significant $(P>0.05)$ differences with the treatments WI and IW in 2006. Similarly, the WI nuts showed significantly $(P<0.05)$ higher disease severity than the I nuts. Nuts of this last treatment (I) showed a few disease symptoms during 2006 and did not show any disease symptoms during 2007, when the treatments WI and IW showed around $40 \%$ disease severity (Fig. 1).

By contrast, when the inoculations were conducted in the field, the SI or IS nuts showed significantly $(P<0.05)$ less severity of disease symptoms than the IW and WI nuts. In this case, the IW nuts showed higher $(P<0.05)$ severity of symptoms than others that WI nuts, although these differences were only significant during 2007. In the field, nonsignificant differences $(P>0.05)$ were observed between treatment I and the noninoculated control nut (Fig. 1A and B).

Effect of the length of time between wounding and inoculation. Trial 2. The first nuts showing typical $N$. mediterraneum lesions where observed in the WI treatment 6 days after inoculation. Conversely, the I nuts (inoculated by depositing a drop of a conidial suspension on the intact nut epidermis) showed very few disease symptoms during this experiment. According to ANOVA, the severity of symptoms of the WI- $0,-4$, or -6 nuts was similar $(P>0.05)$ among them but higher $(P<0.05)$ than the severity of symptoms showed by InjI nuts. Finally, I nuts showed significantly $(P<$ 0.05 ) lower severity of symptoms than that of the remaining treatments (Fig. 2). Noninoculated nuts (controls 1 and 2) did not show any disease symptoms during this experiment; therefore, these treatments do not appear in Figure 2.

Trial 3. When the effect of the length of time between wounding and inoculation and the pistachio cultivar was studied, the three cultivars showed similar $(P=0.217)$ resistance or susceptibility to $N$. mediterraneum for all the treatments (interaction $P=0.9537$ ).

Table 1. Percentage of natural infections on different pistachio tissues caused by Neofusicoccum mediterraneum on four Kerman orchards in California ${ }^{a}$

\begin{tabular}{|c|c|c|c|c|c|c|c|c|c|c|}
\hline \multirow[b]{3}{*}{ Tissue } & \multicolumn{10}{|c|}{ Orchard, year ${ }^{\mathbf{b}}$} \\
\hline & \multicolumn{4}{|c|}{ Glenn } & \multirow{2}{*}{$\begin{array}{c}\text { Merced } \\
2005\end{array}$} & \multicolumn{3}{|c|}{ San Joaquin } & \multicolumn{2}{|c|}{ Yolo } \\
\hline & 2004 & 2005 & 2006 & 2007 & & 2005 & 2006 & 2007 & 2006 & 2007 \\
\hline Fruit & $45.55 \pm 2.30$ & ... & $24.98 \pm 3.45$ & $6.68 \pm 2.07$ & $\ldots$ & $\cdots$ & $32.48 \pm 4.25$ & $\cdots$ & $30.38 \pm 6.34$ & $10.02 \pm 2.07$ \\
\hline Rachis & $55.74 \pm 8.40$ & $4.90 \pm 1.23$ & $35.64 \pm 2.15$ & $3.63 \pm 1.86$ & $1.25 \pm 0.69$ & $2.16 \pm 1.58$ & $12.4 \pm 1.32$ & $2.78 \pm 1.43$ & $33.76 \pm 2.96$ & $0.56 \pm 0.37$ \\
\hline Petiole & $\ldots$ & $2.52 \pm 0.93$ & $23.34 \pm 2.27$ & $3.91 \pm 0.61$ & $\ldots$ & $\ldots$ & $4.29 \pm 0.85$ & $\ldots$ & $4.60 \pm 1.81$ & $\ldots$ \\
\hline Vein & $\ldots$ & $6.05 \pm 0.93$ & $7.71 \pm 1.13$ & $1.96 \pm 0.60$ & $\ldots$ & $\ldots$ & $1.47 \pm 0.55$ & $\ldots$ & $6.05 \pm 1.47$ & $\ldots$ \\
\hline
\end{tabular}

a Samples collected during August to September and isolations conducted on potato dextrose agar amended with lactic acid.

${ }^{\mathrm{b}}$ California counties where orchards were located; average \pm standard deviation of 60 samples. 
By contrast, there were significant differences $(P<0.001)$ between evaluated treatments. For example, the severity of symptoms of nuts of the three cultivars that were inoculated without wounding was $6.3 \%$, whereas the severity of symptoms of nuts that were inoculated immediately after wounding was $89.5 \%$. This last treatment did not show significant differences $(P>0.05)$ with the treatments inoculation 6 and $12 \mathrm{~h}$ after wounding ( 88.1 and $81.5 \%$, respectively). The nuts from the treatment $24 \mathrm{~h}$ after wounding showed higher severity of symptoms $(60.0 \%)$ than nonwounded nuts but lower than the remaining (0-, 6-, and 12-h) treatments (Fig. 3).

Effect of the number and position in the cluster of the nuts infected by $N$. mediterraneum on the blight of clusters. Trial 4. When pistachio nuts were inoculated using a spore suspension or a mycelium plug, there was a significant $(P<0.05)$ effect of the inoculation method (mycelium versus spore suspension), the number of inoculated nuts (from 1 to 5), and the interaction between both independent variables in both years (Fig. 4A). Overall, the final severity of symptoms was higher in the panicles inoculated using a mycelium plug than those inoculated using the spore suspension of the pathogen, with the exception of the one-inoculated-nut treatment conducted during 2006 and three- and five-inoculated-nut treatments conducted during 2007 (Fig. 4B). Furthermore, there was not a clear increase in the severity of symptoms with the number of inoculated nuts, particularly in 2007. Even so, in the first year, there was a positive correlation (Spearman correlation, $P=0.017$ ) between the number of inoculated

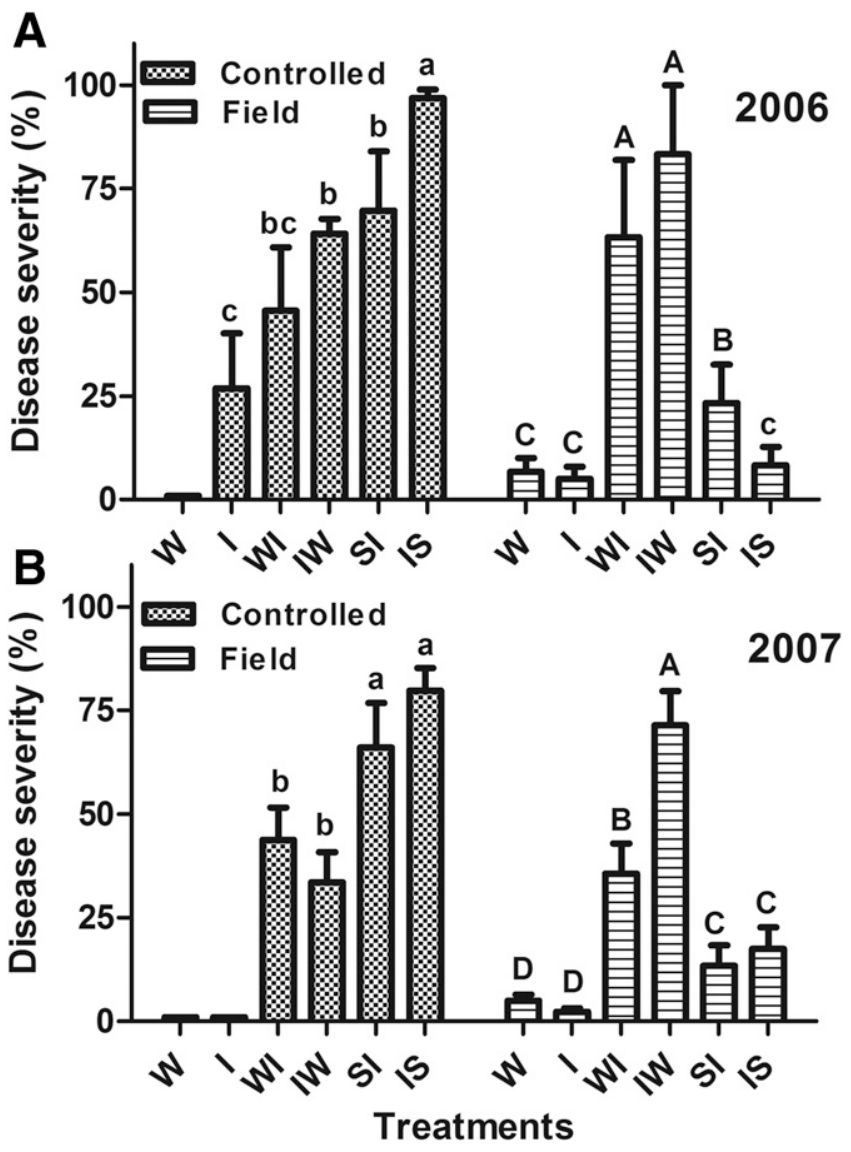

Fig. 1. Effect of wound or addition of nut sap on infection caused by Neofusicoccum mediterraneum on Kerman pistachio nut under laboratory and field conditions in 2006 (A) and 2007 (B). Treatments: W = nut wounded but not inoculated (control), I = inoculated without wounding, $\mathrm{WI}=$ wounded and inoculated $30 \mathrm{~min}$ later, $\mathrm{IW}=$ inoculated and wounded 30 min later, $\mathrm{SI}=30 \mu \mathrm{l}$ of sap applied $30 \mathrm{~min}$ before inoculation, and IS = inoculated and $30 \mu$ l of sap applied $30 \mathrm{~min}$ after inoculation. Nuts for the SI and IS treatments were not wounded. Inoculation consisted of depositing $30 \mu$ l of a $5 \times 10^{4}$ conidia/ml suspension on the nut with a micropipette. Bars represent the average of the treatments and lines represent the standard errors. For each year and condition (field or laboratory conditions), mean values with the same letter are not significantly different according to Fisher's protected least significant difference test at $P=0.05$. nuts by mycelium plug and the final severity of symptoms (Fig. 5A). In the treatment of 5 inoculated nuts using a mycelium plug, the first dead clusters $(5 \%)$ were observed at 12 days after inoculation, whereas the first dead clusters (21\%) appeared 1 month after inoculation when the five nuts were inoculated using a spore suspension. At this time, the $67.4 \%$ of panicles inoculated with a mycelial plug had been killed (blighted) by the pathogen. In 2007, similar differences in the percentage of dead clusters were observed between both treatments (mycelium plug $>$ spore suspension). Furthermore, the severity of symptoms was significantly $(P<0.05)$ higher when the pathogen was directly inoculated in the base of the panicle than when the nuts were inoculated. Thereafter, the incidence of killed clusters 70 days after inoculation was $23.0 \%$ for the nuts inoculated by spore suspension, $50.2 \%$ for nuts inoculated with a mycelium plug, and $66.7 \%$, for inoculations of rachis directly with a mycelium plug (data not shown).

When we studied the effect of position on the panicle of the inoculated nuts (trial 5), there was a significant effect $(P<0.017)$ of year, with 2007 being less conducive to the disease than 2006. For example, the inoculated panicles showed between 9.4 and $26.7 \%$ disease severity when one or two nuts were inoculated during the first year, whereas no symptoms were observed on these treatments during the second year. In both years, there was a significant effect $(P<0.05)$ of the position of nut on the panicle, the number of inoculated nuts, and the interaction between both variables on the severity of symptoms (Fig. 5B).

Trial 6. As expected, under natural conditions, results of severity of symptoms were highly variable. The number of the nuts that initially showed small necrotic spots caused by the pathogen did not significantly $(P<0.05)$ affect the final severity of symptoms in either orchard. The severity of symptoms was slightly higher $(47.8 \pm 9.09 \%)$ in the Glenn orchard than in San Joaquin orchard (37.26 $\pm 5.08 \%)$ (data not shown). Also, none of the tagged panicles from the two orchards were killed during the 42 days of disease evaluation.

Infection pattern of nut, rachis, leaf petiole, and the leaflet midvein. Trial 7. Overall, there were important effects of year and orchard in the percentage of latent infections, with 2004 and 2006 being more conducive for the diseases than 2005 and 2007. For example, the percentages of pistachio rachis infected by $N$. mediterraneum in the Glenn orchard were 57.74, 4.90, 35.64, and 3.63\% for 2004, 2005, 2006, and 2007, respectively. In the San Joaquin orchard, these percentages were $2.16,12.40$, and $2.78 \%$ for 2005,2006 , and 2007 , respectively. According to the percentage of $N$. mediterraneum isolation from the panicle rachis, the disease apparently was more severe in the Glenn and Yolo orchards than in the San Joaquin orchard. In

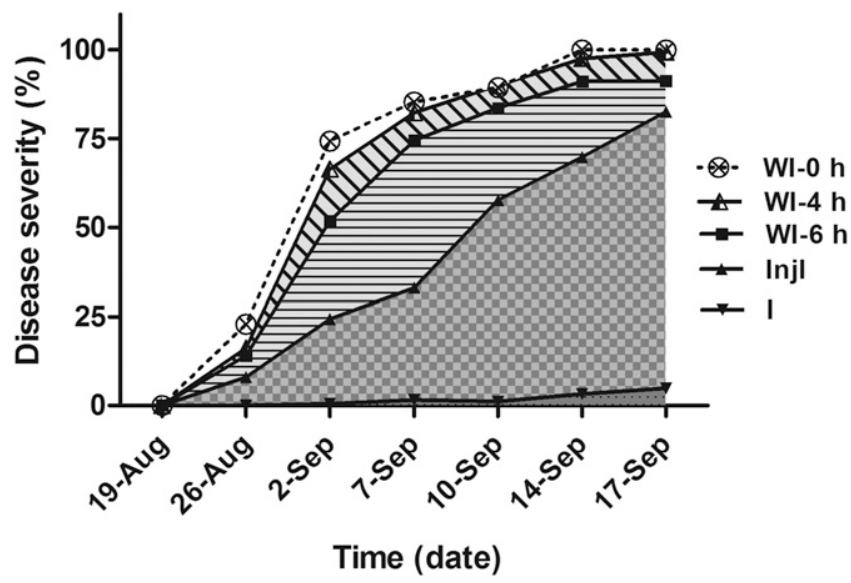

Fig. 2. Effect of the inoculation method and length of time between wounding and inoculation on the progress of severity of symptoms of Kerman pistachio nut inoculated with Neofusicoccum mediterraneum. Treatments: WI-0, -4 , and $-6=$ nut inoculated by depositing a $20-\mu l$ drop of conidial suspension $\left(5 \times 10^{4}\right.$ conidia/ml) on wounded nuts at 0,4 , or $6 \mathrm{~h}$ after wounding, respectively; Injl $=20 \mu \mathrm{l}$ of a conidial suspension was injected under epidermis of each nut using a disposable syringe; and I = a $20-\mu \mathrm{I}-$ conidial suspension drop was deposited on nonwounded nut. Each point represents the average of 40 nuts. 
general, the isolation percentages were higher in the nut and in the rachis than in the leaf petioles and leaflet midveins (Table 1).

There was a significant and positive correlation (Pearson correlation, $P<0.05)$ among the percentages of $N$. mediterraneum isolations from the different plant tissues. For instance, the higher the percentage of $N$. mediterraneum isolation from nuts, the higher the percentage of pathogen isolation from the other plant tissues. Conversely, the isolation percentage was not correlated (Spearman rank correlation, $P>0.05$ ) with the segment position of the different

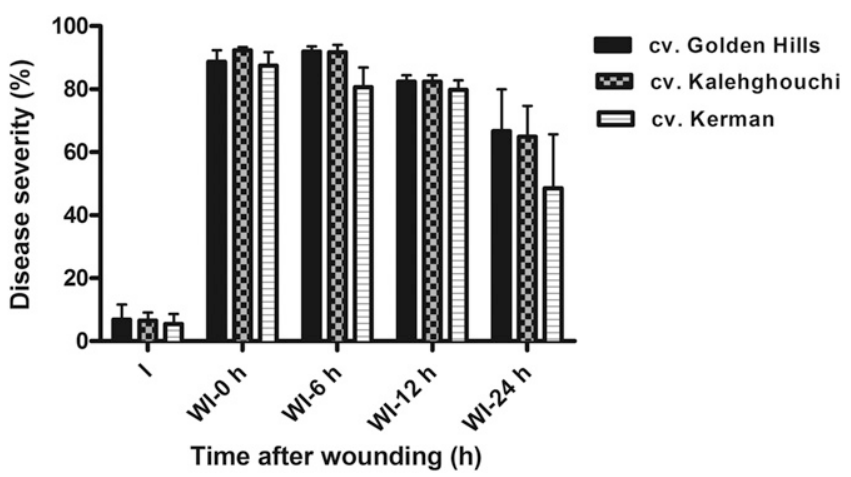

Fig. 3. Effect of the inoculation method and length of time between wounding and inoculation on the progress of symptom severity of Kerman, Kalehghouchi, and Golden Hills pistachio nuts inoculated with Neofusicoccum mediterraneum. Treatments: WI-0, $-6,-12$, and $-24=$ nut inoculated by depositing a $20-\mu$ l drop of conidial suspension $\left(5 \times 10^{4}\right.$ conidia/ml) on wounded nuts at $0,6,12$, and $24 \mathrm{~h}$ after wounding, respectively.
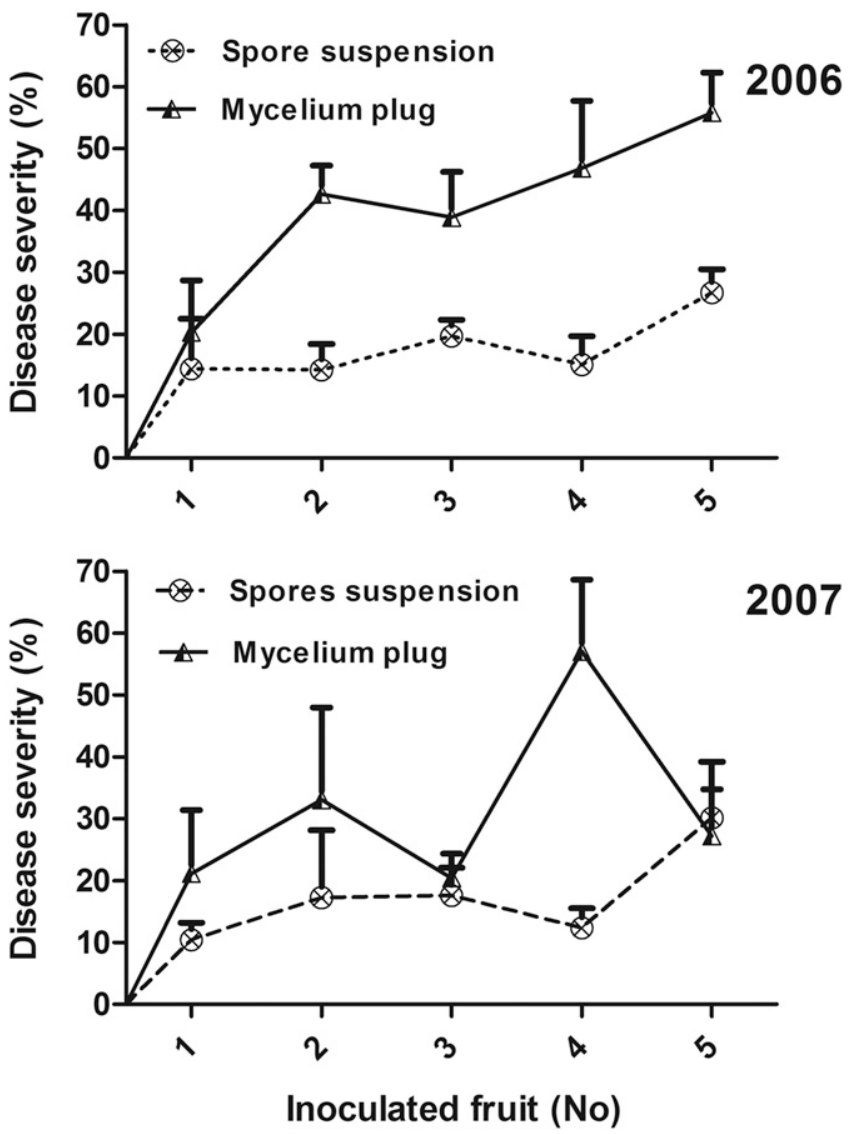

Fig. 4. Effect of the inoculation method and number (from 1 to 5 ) of inoculated nuts on the severity of symptoms of Kerman pistachio nut inoculated with Neofusicoccum mediterraneum in 2006 and 2007. Inoculation methods: (i) placing a 20- $\mu$ l conidial suspension drop on wounded nut or (ii) using a 3-mm mycelial plug of pathogen. Each point represents the average of 12 panicles. tissues (nut, rachis, leaf petioles, and leaflet midveins). For this reason, the different positions within each tissue were considered repetitions. In other words, the different tissues were homogenously colonized by the pathogen.

\section{Discussion}

Wounding nuts or adding sap shortly before or after inoculation increased panicle and shoot blight severity under controlled conditions. In general, nuts inoculated without wounding developed light or no symptoms in our experiments. These results are generally in agreement with those of researchers working on other crops (Brown and Hendrix 1981). Milholland (1972) found that B. dothidea infections were possible on both wounded and nonwounded blueberry stems but necrosis and dieback occurred only after wound inoculation. Infection of nonwounded stems produced small raised lesions that failed to enlarge because the fungus was unable to reach the vascular tissues. Similarly, the pathogen can infect wounded apple tissues more frequently than nonwounded ones but wounding, though important, is not a prerequisite for infection (Brown and Hendrix 1981). The pathogen can use two mechanisms to penetrate intact host tissues: first, chemical penetration due to secreted enzymes by the pathogen (cellulases, pectinases, and so on), which help to breakdown the external plant barriers (cuticle and cell walls) (Andolfi et al. 2011; Esteves et al. 2014); and, second, mechanical penetration due to the development of an appressorium on the spore germ tube that helps, albeit it has been described in a few cases for the Botryosphaeriaceae family (Kim et al. 1999). Neither of these two mechanisms has been described in the pistachio shoot and panicle blight. Nevertheless, Botryosphaeriaceae spp. can cause infection directly through natural openings such as stomata and lenticels (Brown and Hendrix 1981; Michailides 1991).

Age of the wound also played an important role in the susceptibility of plant tissue to Botryosphaeriaceae spp. (Brown and Hendrix 1981). In our experiments, the severity of symptoms of wounded nuts increased $>10$-fold with respect to the severity observed in
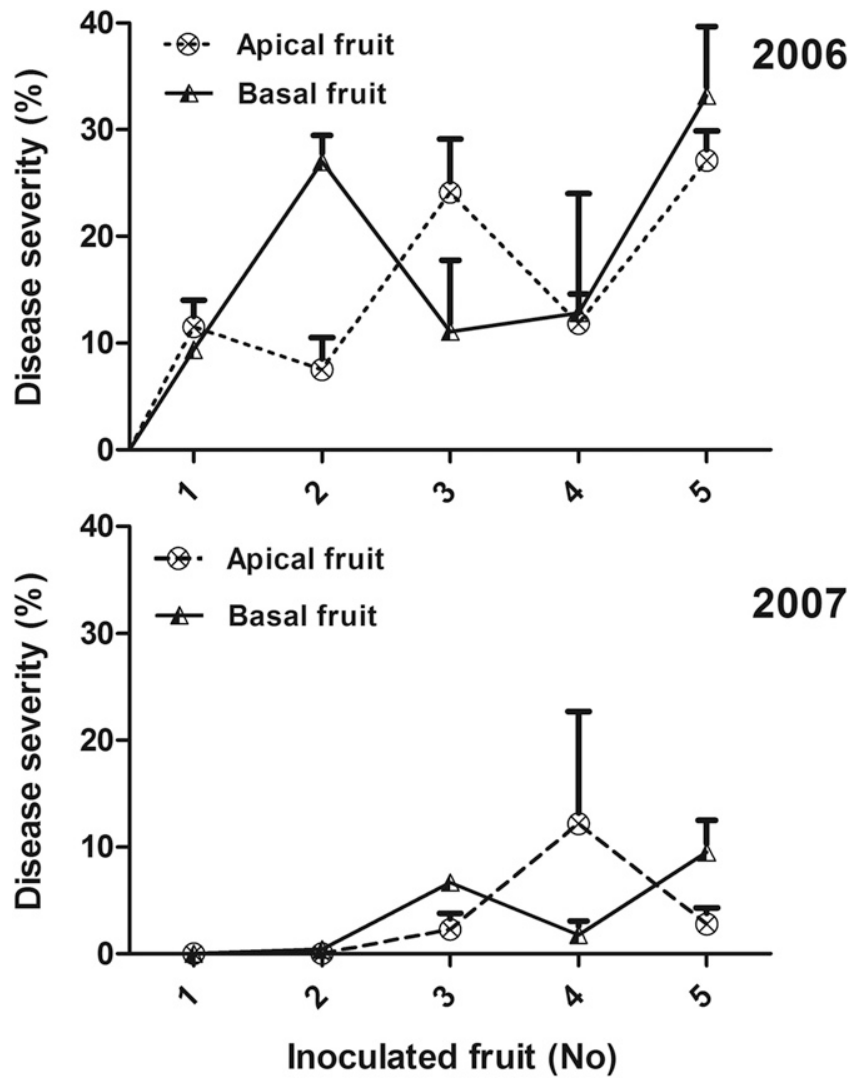

Fig. 5. Effect of the number (from 1 to 5 ) of inoculated nuts and their position on the panicle (apical or basal) in the severity of symptoms of Kerman pistachio nut inoculated with Neofusicoccum mediterraneum in 2006 and 2007. Each point represents the average of 12 panicles. 
nonwounded nuts. This elevated susceptibility of wounded nuts was maintained for at least $24 \mathrm{~h}$. In both trials in which we evaluated the effect of age of wound on disease severity (trial 2 and 3), we observed important differences in the speed of symptom development. For example, in trial 2, the inoculated nuts reached almost the maximum severity of symptoms after 1 month whereas, in trial 3, the maximum severity was reached at 2 weeks after inoculation. This difference could be due to differences between years in which the trials were conducted or differences of virulence between the $N$. mediterraneum isolates. Interestingly, notable differences in genetics (Chen et al. 2014) and on virulence (Moral et al. 2017) have been described between isolates belonging to the species $N$. mediterraneum.

The high susceptibility to the pathogen of wounded nuts has important epidemiological consequences because pistachio trees are punctured by small and large hemipterans insects during the growing season in California (Daane et al. 2000; Michailides et al. 1987). Recently, Michailides and Morgan (2016), working with different large hemipterans insects (A. hilare, L. clypealis, and T. pallidovirens), showed that these insects can facilitate nut infection by $N$. mediterraneum due to punctures in the nut made by them or acting as passive vectors of fungus. Likewise, high incidence of Botryosphaeria canker in walnut branches was associated with high density of scales (Quadraspidiotus juglansregiae) that predispose walnuts to disease (Michailides et al. 2012). Furthermore, other pistachio diseases also can be triggered by wounds caused by insects; for example, the stigmatomycosis of pistachio kernel, caused by the yeast Eremothecium coryli (Peglion) Kurtzman (syn. Nematospora coryli Peglion) and the filamentous fungus Aureobasidium pullulans (de Bary \& Löwenthal) G. Arnaud. The stigmatomycoisis disease develops inside externally sound nuts as a result of punctures caused by hemipteran insects such as T. pallidovirens, L. clypealis, Chlorochroa uhleri, and C. ligata (Michailides et al. 2016). For this reason, the control of hemipteran insects is a recommended practice to reduce this disease intensity in pistachio orchards along with Botryosphaeria panicle and shoot blight.

In recent experiments, we have observed that sap increased disease levels equivalent to the effect of wounding (Michailides and Morgan 2016). In the present work, we observed that the addition of sap onto inoculated nuts increased the severity of symptoms twofold in comparison with the same treatments without sap when the trial was conducted in humid chambers. Under field conditions, conversely, the treatments with sap reduced four-fold the disease severity as compared with the treatments in which the nuts have been wounded and inoculated with the pathogen in the absence of sap. It is expected that the sap dries faster under field conditions than in the laboratory and thus, once dried, it blocks the entry site for the pathogen. Reciprocally, liquid sap can provide nutrients for the pathogen as carbohydrate compounds.

Although female Kerman and male Peters are currently leading $(>90 \%)$ in California pistachio orchards, other cultivars are gradually increasing genetic diversity of this crop in the state. Simultaneously, there is a growing interest in the characterization of the resistance or susceptibility of these cultivars to various diseases, including panicle and shoot blight. In the present study, we characterized the resistance of Golden Hills, coming from a breeding program of the University of California, and Kalehghouchi, a traditional Iranian cultivar (Parfitt et al. 2007). Unfortunately, both cultivars showed a reaction to the pathogen similar to that of susceptible Kerman. Thus far, we have not detected important differences of resistance among these pistachio cultivars, although Kalehghouchi appears to show higher susceptibility (measured as canker length) to Neofusicoccum mediterraneum than Kerman when shoots of these cultivars were inoculated (Michailides et al. 2016).

The number of nuts initially inoculated with a drop of $N$. mediterraneum suspension did not clearly affect the final disease severity in our experiments. When pistachio nuts were inoculated using a conidial suspension, the pathogen killed only $20 \%$ of panicles during the 4-week period after inoculation. During the same time, the pathogen killed approximately $67 \%$ of panicles that were inoculated with a mycelial plug applied in the base of panicles. A similar percentage of blighted panicles was reached in 2007 but one and a half months later, suggesting that this year was less conducive for the disease.
This fact was also observed under field conditions when no panicles blighted by natural infections were observed in Glenn and San Joaquin orchards during this year. Quite to the contrary, during the conducive year 2006, there were 137 and 331 blighted shoots per tree on 29 July and 9 October, respectively, in the Glenn orchard. The fluctuation between epidemic and nonepidemic years of panicle and shoot blight of pistachio is well known (Michailides and Morgan 2004; Michailides et al. 2016) and this fact makes this disease an excellent candidate for applying disease warning systems (Morgan et al. 2009).

This study is also the first report showing the pattern of latent infections caused by $N$. mediterraneum on pistachio nuts, rachises of panicles, and leaf petioles and leaflet midveins of leaves. Overall, the nut and rachis were more susceptible to the pathogen than leaf petioles and leaflet midveins, which showed a similar percentage of infection. No pattern of infection was detected in these organs, probably due to a good distribution of the pycnidiospores within of the pistachio canopy by spring rainfalls. Similarly, pycnidiospores of $N$. mediterraneum can also be released and dispersed by winter rains on the plant surface and then trapped among bud scales (Ahimera et al. 2004), leading to infection of vegetative and reproductive buds. This infection can kill buds entirely or partially, or lead to blighting of developing shoots and panicles in mid- to late spring (Michailides and Morgan 1993).

Previous to this study, we also found that leaves, due probably to their large surface areas intercepting propagules of $N$. mediterraneum in dripping or splashing water, had a higher number of propagules than the nut surface (Ahimera et al. 2003). However, panicles had higher frequencies of latent infection than leaves, suggesting that panicles seem to be more susceptible to infection by the pathogen; and this is why the panicle blight constitutes a major threat to the pistachio crop in California.

In the current study, we identified the plant tissue where most latent infections occur (nuts and rachis), facilitating the assessment of latent infections of the pathogen during the spring. Moreover, we showed that, although the initial infection affects only a few nuts per panicle, it can lead to the entire collapse of the panicle (if weather conditions are conducive) and direct reduction of yields. These facts highlight the importance and necessity of an adequate control of this disease prophylactically to protect the susceptible green pistachio tissues from infection during spring and early summer.

\section{Acknowledgments}

We thank B. Teviotdale for her critical review of the manuscript prior to submission; J. Danforth, M. Beta, A. Papangeli, and G. Driever for their technical assistance; K. Kaplan, R. Schrum, T. Trauba, and J. Maxwell for allowing us to collect samples from their orchards; and the California Pistachio Research Board (formerly California Pistachio Commission) for financial support of this research. J. Moral holds a Marie Skłodowska Curie fellowship launched by the European Union's H2020 (contract number 658579).

\section{Literature Cited}

Adaskaveg, J. E., Gubler, W. D., and Michailides, T. J. 2017. Fungicides, Bactericides, and Biologicals for Deciduous Tree Fruit, Nut, Strawberry, and Vine Crops. University of California Online Statewide IPM Program.

Ahimera, N., Driever, G. F., and Michailides, T. J. 2003. Relationships among propagule numbers of Botryosphaeria dothidea, latent infections, and severity of panicle and shoot blight in pistachio orchards. Plant Dis. 87:846-853.

Ahimera, N., Gisler, S., Morgan, D. P., and Michailides, T. J. 2004. Effects of single-drop impactions and natural and simulated rains on the dispersal of Botryosphaeria dothidea conidia. Phytopathology 94:1189-1197.

Andolfi, A., Mugnai, L., Luque, J., Surico, G., Cimmino, A., and Evidente, A. 2011. Phytotoxins produced by fungi associated with grapevine trunk diseases. Toxins (Basel) 3:1569-1605.

Brown, E. A., and Hendrix, F. F. 1981. Pathogenicity and histopathology of Botryosphaeria dothidea on apple stems. Phytopathology 71:375-379.

Chen, S. F., Morgan, D. P., and Michailides, T. J. 2014. Botryosphaeriaceae and Diaporthaceae associated with panicle and shoot blight of pistachio in California, USA. Fungal Divers. 67:157-179.

Creswell, T. C. and Milholland, R. D. 1987. Responses of blueberry genotypes to infection by Botryosphaeria dothidea. Plant Dis. 71:710-713.

Daane, K. M., Steffan, S. A., Yokota, G. Y., and Michailides, T. J. 2000. Biological investigations of Hemiptera pests to improve control and reduce the spread of the fungus Botryosphaeria dothidea. Pages 19-20 in: California Pistachio Industry, Annu. Rep. Crop Year 1999-2000. Fresno, CA. 
Esteves, A. C., Saraiva, M., Correia, A., and Alves, A. 2014. Botryosphaeriales fungi produce extracellular enzymes with biotechnological potential. Can. J. Microbiol. 60:332-342.

Inderbitzin, P., Bostock, R. M., Trouillas, F. P., and Michailides, T. J. 2010. A six locus phylogeny reveals high species diversity in Botryosphaeriaceae from California almond. Mycologia 102:1350-1368.

Kim, K. W., Park, E. W., and Ahn, K. K. 1999. Pre-penetration behavior of Botryosphaeria dothidea on apple fruits. Plant Pathol. J. 15:223-232.

Michailides, T. J. 1991. Pathogenicity, distribution, sources of inoculum, and infection courts of Botryosphaeria dothidea on pistachio. Phytopathology 81:566-573.

Michailides, T. J., Chen, S. F., Coates, B., Morgan, D., Puckett, R., Hasey, J., Anderson, K., Buchner, R., DeBuse, C., Fichtner, E., and Bentley, W. 2012. Managing anthracnose blight and Botryosphaeria and Phomopsis cankers of walnut. Part 1: Botryosphaeria and Phomopsis of walnut. Pages 367-388 in: Walnut Research Reports 2012. California Walnut Board, Folson.

Michailides, T. J., and Morgan, D. P. 1992. Effects of temperature and wetness duration on infection of pistachio by Botryosphaeria dothidea and management of disease by reducing duration of irrigation. Phytopathology 82:1399-1406.

Michailides, T. J., and Morgan, D. P. 1993. Spore release by Botryosphaeria dothidea in pistachio orchards and disease control by altering the trajectory angle of sprinklers. Phytopathology 83:145-152.

Michailides, T. J., and Morgan, D. P. 2004. Panicle and shoot blight of Pistachio: A major threat to the California pistachio industry. APSnet Feature. Online publication. The American Phytopathological Society, St. Paul, MN. doi: 10.1094/APSnetFeature-2004-0104

Michailides, T. J., and Morgan, D. P. 2016. Association of Botryosphaeria panicle and shoot blight of pistachio with injuries of fruit caused by Hemiptera insects and birds. Plant Dis. 100:1405-1413.

Michailides, T. J., Morgan, D. P., and Doster, M. A. 2016. Foliar, Fruit, and Branch Diseases. Pages 265-291 in: Pistachio Production Manual. L. Ferguson, ed. Center for Fruit and Nut Research and Information, Davis, CA.
Michailides, T. J., Rice, R. E., and Ogawa, J. M. 1987. Succession and significance of several hemipteran insects attacking a pistachio orchard. J. Econ. Entomol. 80:398-406.

Milholland, R. D. 1972. Histopathology and pathogenicity of Botryosphaeria dothidea on blueberry stems. Phytopathology 62:654-660.

Moral, J., Agusti-Brisach, C., Perez-Rodriguez, M., Xavier, C., Raya-Ortega, M. C., Rhouma, A., and Trapero-Casas, A. 2017. Identification of fungal species associated with branch dieback of olive and resistance of table cultivars to Neofusicoccum mediterraneum and Botryosphaeria dothidea. Plant Dis. 101 306-316.

Moral, J., Muñoz-Díez, C., González, N., Trapero, A., and Michailides, T. J. 2010. Characterization and pathogenicity of Botryosphaeriaceae species collected from olive and other hosts in Spain and California. Phytopathology 100:1340-1351.

Moral, J., Pérez-Rodríguez, M., Michailides, T. J., and Trapero, A. 2015. First report of the teleomorph of Neofusicoccum mediterraneum, a pathogen of olive. (Abstr.) Phytopathology 105:S4.97.

Morgan, D. P., Driever, G. F., Felts, D., Krueger, W. H., and Michailides, T. J. 2009. Evaluation of two disease warning systems for Botryosphaeria panicle and shoot blight of California pistachio and efficient control based on earlyseason sprays. Plant Dis. 93:1175-1181.

Ntahimpera, N., Driever, G. F., Felts, D. G., Morgan, D. P., and Michailides, T. J. 2002. Dynamics and pattern of latent infection caused by Botryosphaeria dothidea on pistachio buds. Plant Dis. 86:282-287.

Parfitt, D. E., Kallsen, C., and Maranto, J. 2005. Pistachio cultivars. Pages 62-66 in: Pistachio Production Manual. L. Ferguson, R. H. Beede, M. W. Freeman, D. R. Haviland, B. A. Holtz, and C. E. Kallsen, eds. Fruit and Nut Research and Information Center, University of California, Davis.

Parfitt, D. E., Kallsen, C., Maranto, J., and Holtz, B. 2007. 'Golden Hills' Pistachio. HortScience 42:694-696.

Worrall, J. J., Correll, J. C., and McCain, A. H. 1986. Pathogenicity and teleomorph anamorph connection of Botryosphaeria dothidea on Sequoiadendron giganteum and Sequoia sempervirens. Plant Dis. 70:757-759. 